\title{
Development of chromium and chromium-tungsten alloy for the plasma facing components: Application of vacuum arc melting techniques
}

\author{
D. Terentyev ${ }^{\text {a, }}$, T. Khvan ${ }^{\text {a, b }}$, J.-H. You ${ }^{\text {c }}$, N. Van Steenberge ${ }^{\text {d }}$ \\ a Belgian Nuclear Research Centre, SCK CEN, Mol, 2400, Belgium \\ ${ }^{\mathrm{b}}$ University of Liège, Place du 20 Août 7, 4000, Liège, Belgium \\ c Max-Planck-Institute für Plasmaphysik, 85748, Garching, Germany \\ d OCAS NV, Pres J.F. Kennedylaan 2, 9060, Zelzate, Belgium
}

\section{H I G H L I G H T S}

- Vacuum Arc Melter (VAM) is applied to produce pure $\mathrm{Cr}$ and $\mathrm{Cr}-10 \mathrm{~W}$ solid solution.

- VAM produced $\mathrm{Cr}$ exhibits the transition temperature for ductility being close to room temperature.

- Solid solution with $10 \% \mathrm{~W}$ significantly increases yield strength and work hardening at elevated temperature.
G R A P H I C A L A B S T R A C T

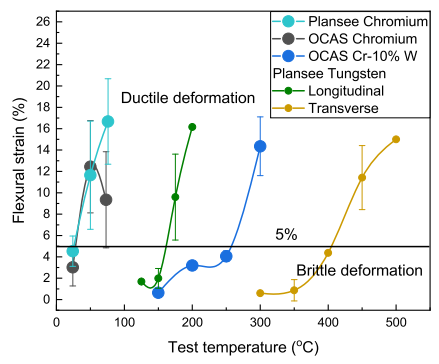

\section{A B S T R A C T}

Design: of plasma-facing components (PFC) for DEMO divertor unravels new challenges to be met by the in-vessel materials. Embrittlement induced by 14 MeV neutrons in the baseline first wall material -tungsten (W) endangers structural integrity of PFCs. Chromium (Cr) and/or $\mathrm{Cr}-\mathrm{W}$ alloy is currently considered as a candidate material in the design of mid heat flux PFCs as structural body of the monoblock. $\mathrm{Cr}$ has the superior mechanical properties in the low temperature range where the com-mercial tungsten products are brittle. However, the fabrication of $\mathrm{Cr}$ requires high level purity control and is therefore challenging for mass production.

In this work, vacuum arc melting (VAM) equipment is employed for the fabrication of chromium ( $\mathrm{Cr}$ ) and $\mathrm{Cr}$-10at.\%W alloy targeted for the PFC applications. VAM techniques represents new promising alterna-tive route with a high upscale potential. VAM fabrication improves $\mathrm{Cr}$ quality by avoiding the intro-duction of interstitial impurities, while the produced ingots can be further mechanically treated as well as solution alloyed by $\mathrm{W}$ to design a dedicated microstructure thus enhancing important mechanical properties, e.g. yield strength and fracture toughness.

The produced heats of pure $\mathrm{Cr}$ and $\mathrm{Cr}-10 \mathrm{~W}$ are investigated by means of chemical and microstructural analysis as well as by mechanical testing. The obtained results are compared with those obtained for pure $\mathrm{Cr}$ and $\mathrm{W}$ products fabricated by Plansee (Austria). The VAM-produced pure $\mathrm{Cr}$ (without any thermo-mechanical optimization) shows the transition to ductility deformation mode just above the room temperature proving the principal advantage of this fabrication route. Solid solution with $10 \%$ of W significantly improves the proof stress while sustaining good ductility at elevated temperatures. The ductile to brittle transition in $\mathrm{Cr}-10 \% \mathrm{~W}$ is observed around $300^{\circ} \mathrm{C}$, which likely can be reduced further by thermo-mechanical treatment. The bending strength of the tested pure $\mathrm{Cr}$ grades is considerably lower than that of pure tungsten, when compared at the technologically relevant temperature i.e. $300-500{ }^{\circ} \mathrm{C}$. Whereas the bending strength of $\mathrm{Cr}-10 \% \mathrm{~W}$ constituted about $80 \%$ of the strength of pure tungsten. Hence, the developed VAM $\mathrm{Cr}$ and $\mathrm{Cr}-\mathrm{W}$ alloys require a next step assessment with respect to neutron irradiation testing and improvement by thermo-mechanical treatment.

\footnotetext{
* Corresponding author.

E-mail address: dterenty@sckcen.be (D. Terentyev).
} 


\section{Introduction}

Chromium ( $\mathrm{Cr}$ ), group VI element with the body centered cubic (BCC) lattice structure and melting point of $1907{ }^{\circ} \mathrm{C}$, is included in the wider definition of the refractory metals. $\mathrm{Cr}$ and chromiumbased alloys have been studied since decades as candidates for high-temperature applications in jet engines [1,2] and in plasmafacing components of the fusion reactor vessel $[3,4]$. $\mathrm{Cr}$ exhibits a number of properties which makes it good candidate for the application in the plasma facing components such as: high strength-to-density ratio, high melting point (being $1863^{\circ} \mathrm{C}$ [5]), an excellent corrosion resistance [6,7]. The last stands due to the protective $\mathrm{Cr}_{2} \mathrm{O}_{3}$ layer which remains stable up to $1400{ }^{\circ} \mathrm{C}$, and makes the material extremely resistant to environmental corrosion. Finally, an application of $\mathrm{Cr}$ is also favorable from the viewpoint of the neutron irradiation activation, as according to the neutronic calculations, plasma-facing components for fusion reactor made of $\mathrm{Cr}$ can be classified as low-level waste already after 50 years of cooling $[4,8]$.

Despite the above listed advantages, application of $\mathrm{Cr}$ has two important issues that need to be addressed prior its consideration in the design. Firstly, the production technology of high purity $\mathrm{Cr}$ is important because even a low level contamination by oxygen and nitrogen causes reduction of the ductility at room temperature (which impacts the workability, formability and welding/brazing of the material). Secondly, the impact of $14 \mathrm{MeV}$ neutrons on the ductile-to-brittle transition temperature (DBTT) and potential plastic-flow instability, as it is well known to occur in the case of ferritic steels $[9,10]$, needs to be explored.

As was reviewed in Ref. [11], certain $\mathrm{Cr}$ grades and $\mathrm{Cr}$-based alloys were developed for the application in fuel cells as structural material by Plansee AG (Austria). Mechanical properties of those pure $\mathrm{Cr}$ (Ducropur) and Cr-based alloys with addition of oxide strengthening particles were studied by Holzwarth and Stamm [11]. The material was produced at industrial scale and was available in the plates with a thickness of up to $15 \mathrm{~mm}$. The base material for the production was electrolytically deposited and degassed $\mathrm{Cr}$ powder. Mechanical properties were characterized by performing tensile and fracture toughness tests in air in the temperature range of RT- $1000{ }^{\circ} \mathrm{C}$. The results demonstrated that the DBTT of Ducropur grade was about $100-200{ }^{\circ} \mathrm{C}$, depending on definition applied (i.e. from tensile or fracture toughness tests). Tensile tests performed up to $100{ }^{\circ} \mathrm{C}$ showed rather low elongation to fracture (few percent or even less), which is likely related to the residual impurity content, as the obtained material was $99.7 \%$ pure with about 50 wt. ppm of nitrogen [11]. Hence, the improvement of purity of $\mathrm{Cr}$ may potentially improve its mechanical properties in terms of the reduction of DBTT. On the other hand, one could also expect that a solid solution of $\mathrm{Cr}$ with another transition refractory metal (e.g. tungsten) could promote the strength and toughness without the reduction of the corrosion and thermal properties. With this respect, the mixture of chromium-tungsten $(\mathrm{Cr}-\mathrm{W})$ solid solution alloy could potentially generate a refractory material with attractive properties. An addition of limited amount of tungsten (up to $10 \%)$, to respect the solubility limit $[12,13]$, should theoretically improve the strength (due to solid solution and grain boundary pinning) without altering the thermal conductivity. Additionally, the solid solution alloying may also improve the resistance to neutron irradiation damage $[14,15]$. In the case of the $\mathrm{Fe}-\mathrm{Cr}$ system (basis for high temperature steels), which is also bcc solid solution as $\mathrm{Cr}-\mathrm{W}$, it has been demonstrated that 9 at.\% $\mathrm{Cr}$ alloy exhibits an optimized performance in terms of the void swelling [16,17]. As long the concentration of the alloying element is within solubility limit, the solutes have homogeneous distribution (i.e. random solid solution) in the matrix, while above this concentration the precipitation of alpha prime particles occurs [18-20] leading to embrittlement [21]. The resistance to swelling by the solid solution could be improved thanks to the alternation of the accumulation of the irradiation defects [22,23], in particular linked to the diffusion and trapping of the dislocation loops [24,25], whose storage offers extra sites for recombination, as was discussed for the $\mathrm{Fe}-\mathrm{Cr}$ system [26,27].

In this work, for the first time, we apply the vacuum arc melting (VAM) equipment to fabricate ingots of $\mathrm{Cr}$ and $\mathrm{Cr}-10 \mathrm{at} . \% \mathrm{~W}$ alloy. The VAM techniques allows one to obtain superior control over the chemistry during the melting process and avoid inclusion of such detrimental elements like oxygen and nitrogen. The VAMfabricated ingots were re-annealed in the induction furnace to achieve uniform microstructure and chemical heterogeneity. The fabricated material was characterized in terms of its chemical composition, microstructure and mechanical properties. The microstructure was characterized by electron back scattering diffraction techniques, while the mechanical properties were obtained by instrumented hardness, Vickers hardness and bending tests. The properties of VAM-produced materials were compared with the pure $\mathrm{Cr}$ and $\mathrm{W}$ produced by conventional powder metallurgy by Plansee.

\section{Experimental details}

\subsection{Fabrication of $\mathrm{Cr}$ and $\mathrm{Cr}-\mathrm{W}$ alloy}

Most of industrial metals and alloys, such as steels, aluminum and copper, are produced by melting and casting in a mould. For this kind of production, OCAS $<\mathrm{SUP}>\mathrm{NV}</$ SUP $>$ uses vacuum induction furnace, levitation smelter or air casting. However, none of these technologies is able to reach the temperature necessary to melt refractory metals such as e.g. tungsten (melting point $3422^{\circ} \mathrm{C}$ ). Therefore, in this work, for the production of $\mathrm{Cr}$ and $\mathrm{Cr}-\mathrm{W}$ alloys a new vacuum arc melter (VAM) furnace was utilized.

The material components are deployed on the copper mould such as shown in Fig. 1 (a) and (b) for chromium and tungsten, respectively. The vacuum chamber consists of a base plate and double-walled stainless steel container with a movable feedthrough for the electrode. A copper crucible mould is located on the base plate to store material during the melting, see Fig. 1(c). The mould is cooled by the water at $13{ }^{\circ} \mathrm{C}$ during the melting. Before each melt run, the copper mould is cleaned with isopropanol to 

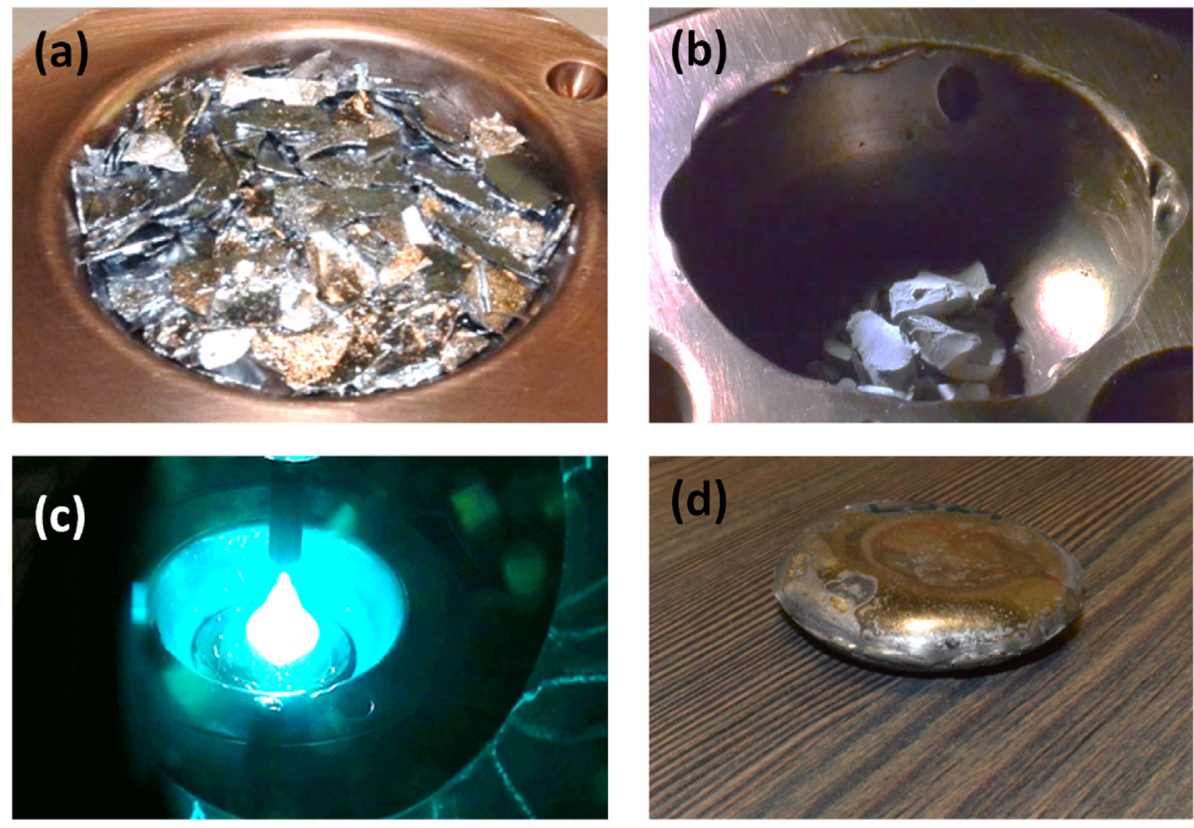

Fig. 1. Application of VAM to produce an ingot of pure $\mathrm{Cr}$ or $\mathrm{Cr}-\mathrm{W}$ alloy. (a) Chromium flakes. (b) Tungsten lumps; (c) melting of the ingot; (d) final ingot of $271 \mathrm{~g}$.

avoid any contamination from dust or the previous melt.

Vacuum pumping consists in a number of steps. At first, the vacuum of $10^{-2}$ mbar is reached using the primary pump. Then, the chamber is filled with argon, creating protective oxygen-reduced atmosphere, and the primary vacuum pump operates again to get $5 \cdot 10^{-2}$ mbar to enable starting the turbo pump. Turbo pump creates a pressure of $5 \cdot 10^{-5}$ mbar followed by the second argon injection prior the melting processes is started. Once the melting process is finalized, one must let the complete cooling of the ingot to avoid internal oxygen contamination.

Due to the active cooling of the $\mathrm{Cu}$ mould, the molted ingot experiences temperature gradient during solidification which may cause some heterogeneity of the microstructure and mechanical properties. Thus, the ingot produced by the VAM was placed in the induction furnace to obtain the homogeneous microstructure. The ingots are placed in an alumina crucible which can support temperature up to about $2000{ }^{\circ} \mathrm{C}$. This temperature is very close to the melting point of $\mathrm{Cr}-10 \mathrm{~W}$ alloy, which we target to produce in this work. Thus, for our purpose, alumina crucible was sufficient to homogenize the microstructure of the VAM-produced ingots of pure $\mathrm{Cr}$ and $\mathrm{Cr}-10 \mathrm{~W}$. The cooling down of the ingots in the crucible after the induction reheat took about 8-12 h to ensure homogenous temperature reduction. The reduction of the temperature was followed by regular measurements.

Two different raw $\mathrm{Cr}$ components were tried in this work, namely: lumps and flakes with the purity of 99.74 at.\% and 99.97 at.\%, respectively. Main impurities, as specified by the suppliers, were oxygen, silicon and iron. For tungsten, the lumps of 99.95 at.\% purity were used. For the most pure materials, whose characterization is provided below, three batches for each pure $\mathrm{Cr}$ and $\mathrm{Cr}-10 \% \mathrm{~W}$ were fabricated. The weight of each batch is about $300 \mathrm{~g}$. The isotopic composition of the constituents was not checked, however, it is assumed that they have natural isotopic composition.

In addition to the VAM produced materials, we have included pure $\mathrm{Cr}$ produced by Plansee using powder metallurgy method. This material represents high purity commercially available $\mathrm{Cr}$ whose production process can be scaled up if needed. The Cr plate of $4 \mathrm{~mm}$ thickness was provided by IPP Garching. The commercially pure $\mathrm{Cr}$ (>99.8\%) was supplied. The nominal chemical composition specified by the supplier contains the following impurities (with amount not exceeding): Fe 300, Si 100, W 50, Mo 50, C 100, O 300, N 200 , measured in $\mu \mathrm{g} / \mathrm{g}$ i.e. weight $\mathrm{ppm}$. To provide the comparison with the reference first wall material for the high heat flux region, we have included commercially pure tungsten also produced by Plansee (square rod of $36 * 36 \mathrm{~mm}^{2}, 99.97 \%$ purity) which was hammered and stress released at $1000{ }^{\circ} \mathrm{C}$ for $1 \mathrm{~h}$. Note that tungsten is selected as main candidate material for the first wall in the divertor and armour of blanket components in DEMO [28]. This material has been characterized in terms of microstructure and mechanical properties in our earlier works [29-31]. The tungsten product has a texture and therefore the tests were performed for longitudinal (L-T) and transversal (T-L) directions.

\subsection{Experimental characterization}

The produced ingots were cut by electric discharge machine on samples to perform chemical and microstructural analysis as well as mechanical testing.

Three different types of chemical analyses were applied to determine the concentration of impurities and the chemical homogeneity of the ingots produced. Oxygen contamination of the material is determined by a combustion analysis. Such technique allows determination of the bulk concentration of $\mathrm{C}, \mathrm{S}, \mathrm{N}, \mathrm{O}$ and $\mathrm{H}$ in solid samples. The reaction gases are detected by infrared absorption detectors for $\mathrm{C}, \mathrm{S}$ an $\mathrm{O}$ and by thermal conductivity detectors for $\mathrm{N}$ and $\mathrm{H}$. Chips of about $1 \times 1 \times 1 \mathrm{~mm}^{3}$ volume were used for this analysis.

$\mathrm{X}$-Ray fluorescence was used to determine the presence of $\mathrm{Fe}, \mathrm{Al}$ and Si elements. Energy Dispersive X-Ray (EDX) was used to analyze the chemical homogeneity of the ingots in different parts. To obtain quantitatively correct result on the elemental composition of the $\mathrm{Cr}-10 \mathrm{~W}$ alloy, the $\mathrm{X}$-ray fluorescence (XRF) intensities were converted in concentrations using a calibration line which was set up based on the reference data obtained using the pure metal samples. The EDX was applied using a scanning electron 
microscope (SEM) JEOL6610. For these two techniques, a flat tile polished samples of $10 \times 10 \times 1 \mathrm{~mm}^{3}$ size were used. The same sample was also used for the electron back scattering diffraction (EBSD) analysis performed with Bruker QUANTAX secondary electron detector integrated in SEM JEOL6610 at $25 \mathrm{kV}$ and then mapped by Bruker QUANTAX software with the spot size of 50 . The fracture surface of the mechanical samples was studied by the same SEM and secondary electron detector combination using the acceleration voltage of $15 \mathrm{kV}$.

Mechanical testing was performed by applying Vickers Hardness $(\mathrm{VH})$ tests, instrumented nanoindentation testing and three point bending tests. The bending tests were applied using environmental furnace operating in the temperature range -150 to $600{ }^{\circ} \mathrm{C}$.

For the Vickers hardness tests the force applied was varied (up to $0.2 \mathrm{kgf}$ ) and the hold time was set to $10 \mathrm{~s}$. The depth of the probed material in this case corresponds to about $10-50 \mu \mathrm{m}$. After the load is removed, the two imprinted diagonals $d_{1}$ and $d_{2}$ are measured and averaged such that Vickers hardness is calculated as $H V=\frac{1854,4 L}{d^{2}}$

Nanoindentation of the samples was performed using a Keysight G200 Nano Indenter to measure the Young's modulus and hardness. The indentation measurements were performed in continuous stiffness mode (CSM) with the standard XP head equipped with a Berkovich diamond tip. The oscillation amplitude and frequency were respectively $2 \mathrm{~nm}$ and $45 \mathrm{~Hz}$. The indentation strain rate was set to $0.05 \mathrm{~s}^{-1}$ and the specimens were indented down to a penetration depth $h<S U B>N I</ S U B>=1.5 \mu \mathrm{m}$. Two zones per sample were investigated by performing 25 indents arranged in $5 \times 5$ square shape and spaced by a distance of $60 \mu \mathrm{m}$. The hardness and Young's modulus were calculated using the classical Oliver \& Pharr method [32]. Calibration for the tip area function was performed by carrying out a series of indents in a reference fused silica sample. The same experimental techniques were applied earlier to study tungsten after plasma and high temperature exposures in Ref. [33-35].

Three point bending ( $3 \mathrm{~PB}$ ) tests were applied on the flat square bar samples of $1 \times 1 \times 12 \mathrm{~mm}^{2}$ size. The tests were performed according to the ASTM E399 standard [36]. The 3 PB test setup is designed following the ASTM E290 standard [37]. The flexural strain (FS\%) is calculated as $F S \%=\frac{6 D d}{L^{2}}$, where $D$ is the maximum deflection of the 3 PB specimen, $d$ is the thickness of the specimen, and $L$ is the supporting span of the test stage (in this case $L=8.5 \mathrm{~mm}$ ). The tests were performed in air in the temperature range from 0 to $500{ }^{\circ} \mathrm{C}$ on a standard INSTRON 3800 universal mechanical testing machine. For the determination of the ductile to brittle transition temperature region, we used a criterion basing on the flexural strain prior to fracture. For the first time, the criterion was proposed in the study of ductility of tungsten at Lawrence Livermore national laboratory [38]. The transition temperature for ductility was defined as the temperature at which the flexural strain equals or exceeds $5 \%$, which had been applied later on by other researches for tungsten based materials [39,40]. A recent work dedicated to the validity of this approach has shown the good basis behind this criterion by comparing the results obtained from miniaturized 3 PB and compact tension fracture toughness samples [31].

\section{Results}

\subsection{Chemical and microstructural analysis}

The chemical analysis was performed by three methods using XRF, SEM-EDX and combustion analysis. The main purpose of the analysis was to ensure that no chemical contamination occurred during the production of the chunk as well as to check the homogeneity of the chemical composition in the chunk across its length and thickness. Firstly, the combustion and XRF analysis were performed to deduce the chemical composition. $\mathrm{Fe}$ and $\mathrm{O}$ were revealed to be the main residual elements, found in the produced chunks. The results are shown in Table 1, where we also add the data for Plansee $\mathrm{Cr}$. As we can see, there are negligible traces of Fe and $\mathrm{O}$ in VAM $\mathrm{Cr}$, while their content is higher in VAM $\mathrm{Cr}-10 \mathrm{~W}$, which is likely due to the purity of tungsten lumps. However, if one compares the content of $\mathrm{Fe}$ and $\mathrm{O}$ with Plansee $\mathrm{Cr}$, we clearly see that VAM $\mathrm{Cr}-10 \mathrm{~W}$ has a similar purity.

The chemical homogeneity was checked by analyzing eight different zones in each of the produced chunk. In the case of pure $\mathrm{Cr}$, the chemical composition was fully homogenous within instrumental uncertainty of the measurements. In the case of $\mathrm{Cr}-10 \mathrm{~W}$ chunk, some zones with the chemical composition deviating from the nominal one were detected. These zones were limited to few micrometers in size and chemical mapping demonstrated that these are $\mathrm{Al}_{2} \mathrm{O}_{3}$ oxides which apparently originated from the application of $\mathrm{Al}$ crucible. The analysis of $\mathrm{Cr}$ and $\mathrm{W}$ has demonstrated that $\mathrm{Cr}$ distribution is completely homogeneous as should be expected from the selected annealing temperature.

SEM-EBSD analysis was applied in several regions on the VAMproduced chunks and on samples cut from the Plansee plate to ensure the homogeneity of the microstructure of these products. Fig. 2 presents typical EBSD maps obtained. In the case of Plansee material, the samples were cut to check the microstructure in the longitudinal and transversal directions, since the material was supplied in a form of a plate. VAM $\mathrm{Cr}$ has large grains, separated with straight high angle grain boundaries, as one can see from Fig. 2(a). The average grain size is $\sim 650 \mu \mathrm{m}$. VAM $\mathrm{Cr}-10 \mathrm{~W}$ has twice as small grain size of about $340 \mu \mathrm{m}$ on average. Thus, the addition of W suppresses the grain growth during the solidification process as well as during the high temperature annealing applied to homogenize the chemical and microstructural state. In the case of Plansee $\mathrm{Cr}$, the average grain size is 150 and $168 \mu \mathrm{m}$ as measured for T and $\mathrm{L}$ orientations, respectively. The grains do not have any evident texture, but the width of the grain size distribution is much wider compared with the VAM products.

\subsection{Mechanical testing}

Three point bending ( $3 \mathrm{~PB}$ ) tests were performed in air, since we did not expect any oxidation of the materials in the temperature range of the ductile to brittle transition. As explained in Section 2, to identify the transition region, we measure the maximum flexural strain and deduce the temperature at which it exceeds $5 \%$, following the criteria proposed in Refs. [38] for another refractory metal - tungsten. Typical examples of the flexural stress - flexural strain $(S-\varepsilon)$ curves for the products tested near the transition temperature are shown in Fig. 3. Given the applied fixture and geometry of the samples, the deformation above $10 \%$ of the flexural strain is influenced by the friction on rolling pins and local deformation induced by the indenting pin. However, this does not impact an accurate determination of the temperature at which the flexural strain exceeds 5\% with reliable statistics. Moreover, for the samples which reached the flexural strain of $20 \%$ the tests were stopped, as it was clear that the deformation occurred in the fully ductile mode.

Besides the flexural strain, it is worth to discuss the flexural stress measured for the studied materials. The transition from the linear to the plastic response in $3 \mathrm{~PB}$ tests correlates with the yield strength of the material. From the results presented in Fig. 3, it is clear that the flow stress of the VAM $\mathrm{Cr}-10 \mathrm{~W}$ is essentially higher than that of pure $\mathrm{Cr}$ products. The lowest temperature at which the 
Table 1

Results of chemical analysis obtained using XRF. *The data for Ducropur Cr are taken from Ref. [11].

\begin{tabular}{|c|c|c|c|c|c|}
\hline Material & $\mathrm{Cr}$ [mass \%] & W [mass \%] & Fe [mass \%] & $\mathrm{O}$ [mass \%] & $\mathrm{O}$ in raw material \\
\hline VAM Cr & 99,95 & & 0,0025 & 0,005 & 0003 \\
\hline VAM $\mathrm{Cr}-10 \% \mathrm{~W}$ & 90,50 & 9,1 & 0,1 & 0,07 & 0,003 \\
\hline Plansee $\mathrm{Cr}$ & 99,8 & & 0,078 & 0,05 & Not specified \\
\hline Ducropur Cr* & 99.7 & & $<0.25$ & 0.01 & Not specified \\
\hline
\end{tabular}

(a) $\mathrm{VAM} \mathrm{Cr}$

Avg. grain size $\approx 653,1 \mu \mathrm{m}$
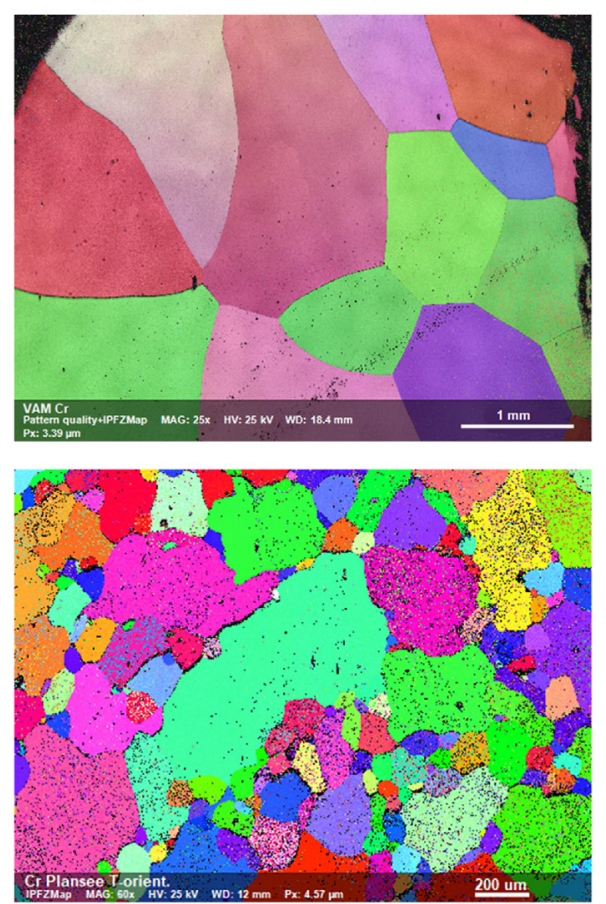

(c) Plansee $\mathrm{Cr}$ T-orientation

Avg. grain size $\approx 151,08 \mu \mathrm{m}$ (b) VAM $\mathrm{Cr}-10 \%$ W

Avg. grain size $\approx 340,57 \mu \mathrm{m}$
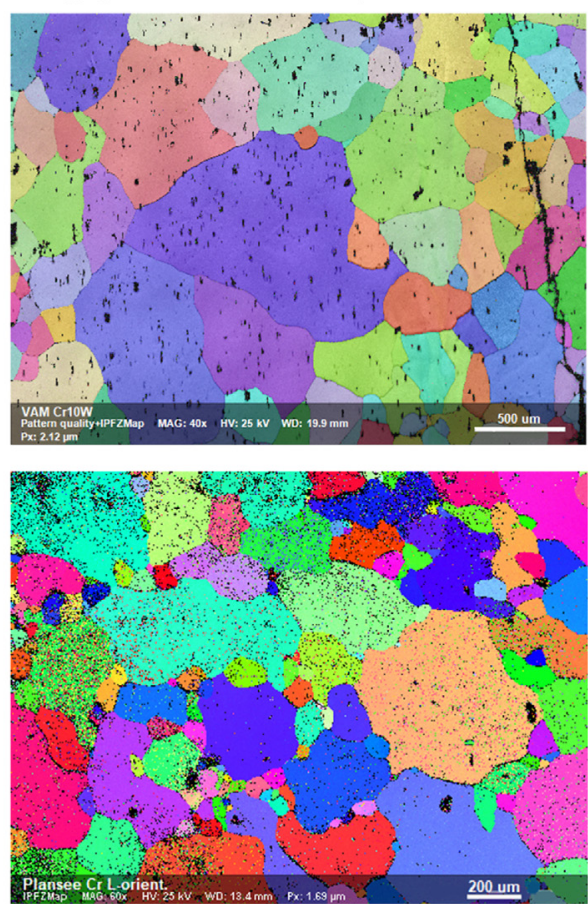

(d) Plansee $\mathrm{Cr}$ L-orientation

Avg. grain size $\approx 168,03 \mu \mathrm{m}$

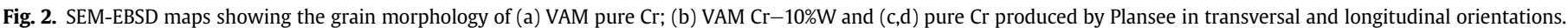

transition from linear to plastic response was observed in the VAM $\mathrm{Cr}-10 \mathrm{~W}$ is $150^{\circ} \mathrm{C}$, where the flexural strain at rupture did not yet reach the threshold of $5 \%$. However, one can see that the inflection from elastic to plastic takes place at the stress around $450 \mathrm{MPa}$, while it is only $200 \mathrm{MPa}$ for the pure Cr products. In Fig. 5, we provide the comparison of the S- $\varepsilon$ curves obtained at $300{ }^{\circ} \mathrm{C}$ and $500^{\circ} \mathrm{C}$, where all tested products are fully ductile.

The flexural strain at fracture (i.e. maximum flexural strain) vs. test temperature is presented in Fig. 4 for pure $\mathrm{Cr}, \mathrm{Cr}-10 \mathrm{~W}$ and pure W (Plansee, double forged bar, characterized in Ref. [29-31]). Since, pure tungsten product has a texture, the results for L-T and T$\mathrm{L}$ directions are provided.

As one can see from Fig. 4, pure $\mathrm{Cr}$ products exhibit the transition to ductility in the temperature range $25-50{ }^{\circ} \mathrm{C}$. At this, VAM $\mathrm{Cr}$ has rather large grains and fully stress-relieved (even recrystallized) structure due to high temperature annealing unlike Plansee $\mathrm{Cr}$. Thus, it is logical to expect that further thermo-mechanical treatment aiming at refining grain size and increasing dislocation density will lead to the reduction of the transition temperature and increase of the strength, as was demonstrated in the case of tungsten recently by reducing its DBTT by few hundreds degrees [41].

VAM $\mathrm{Cr}-10 \mathrm{~W}$ product exhibits the transition in the range of
$250-300{ }^{\circ} \mathrm{C}$. Such high transition temperature should be attributed to the solid solution strength and smaller grain size (as was confirmed by EBSD). It is also expected that the material exhibits rather low dislocation density, since it was annealed at $2000{ }^{\circ} \mathrm{C}$ to homogenize the chemical composition after the melting. This material should also have a high potential of ductilization by thermomechanical treatment as discussed above for VAM pure $\mathrm{Cr}$.

The flexural stain at fracture for the pure $\mathrm{W}$ is also added in Fig. 4. As one can see, tungsten samples with the T-L orientation have the highest transition temperature being about $400{ }^{\circ} \mathrm{C}$. In the $\mathrm{L}-\mathrm{T}$ orientation, tungsten exhibits a transition in the range $150-175^{\circ} \mathrm{C}$, which is below the one of the VAM $\mathrm{Cr}-10 \mathrm{~W}$ material.

To provide a picture reflecting the mechanical performance of the materials tested in equivalent conditions, we have performed a set of $3 \mathrm{~PB}$ tests at $300{ }^{\circ} \mathrm{C}$ and $500{ }^{\circ} \mathrm{C}$, where all four materials exhibit ductile behavior (except T-L tungsten sample at $300^{\circ} \mathrm{C}$ ). The 3 PB $S-\varepsilon$ curves are presented in Fig. 5 from which one can single out the following trends: (i) pure $\mathrm{W}$ has the highest flow stress, while $\mathrm{Cr}$ has the lowest one; (ii) $\mathrm{t}$ the response of the VAM Cr and Plansee $\mathrm{Cr}$ is very similar at both temperatures; (iii) VAM $\mathrm{Cr}-10 \mathrm{~W}$ material exhibits considerable work hardening (compared to pure $\mathrm{Cr}$ ) yielding to an essential increase of the flexural stress at rupture compared with the stress at the elastic-plastic transition. The above 

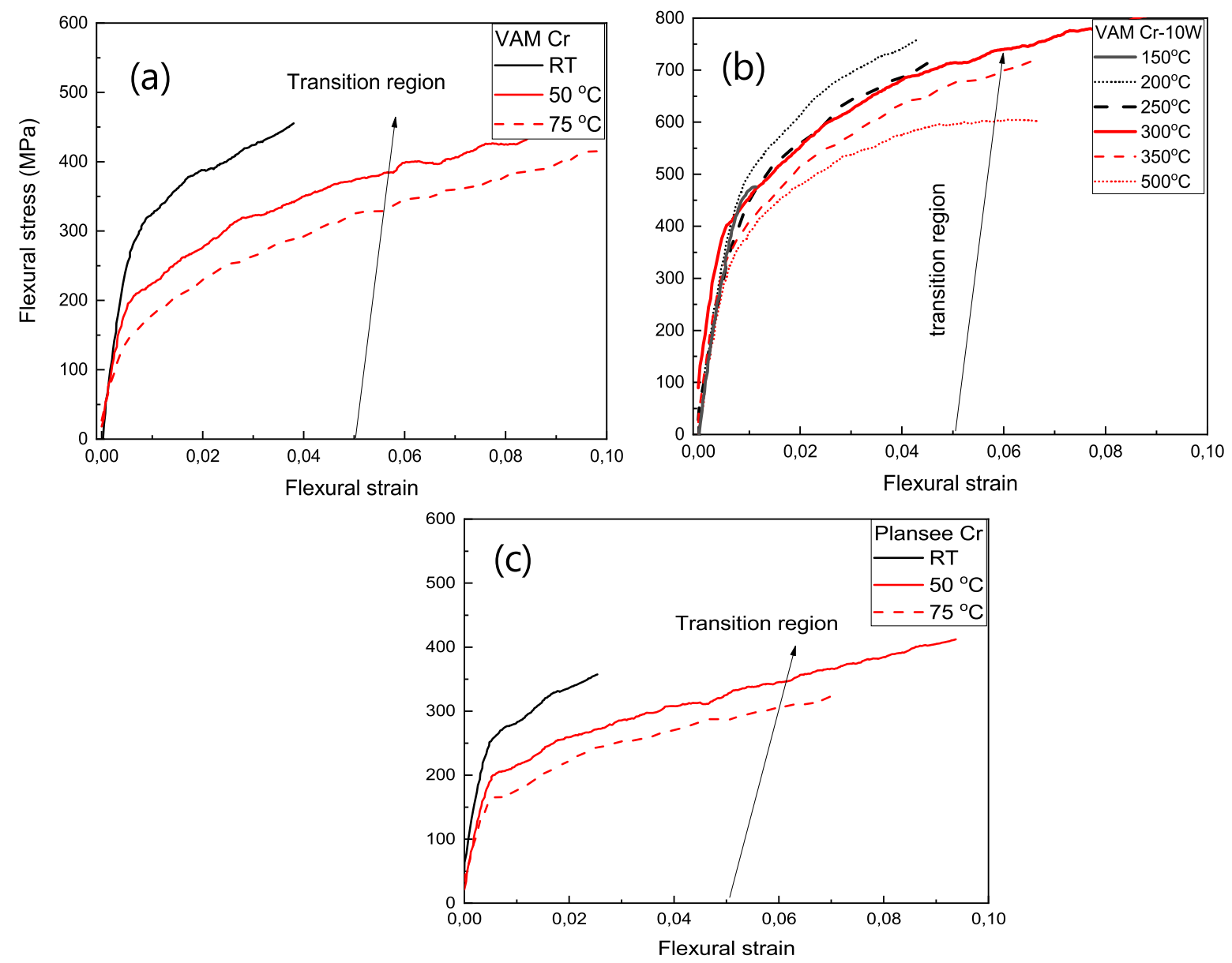

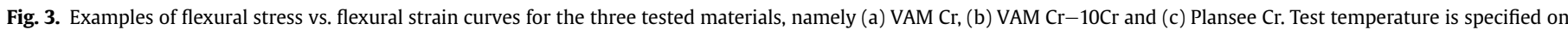
the legends.

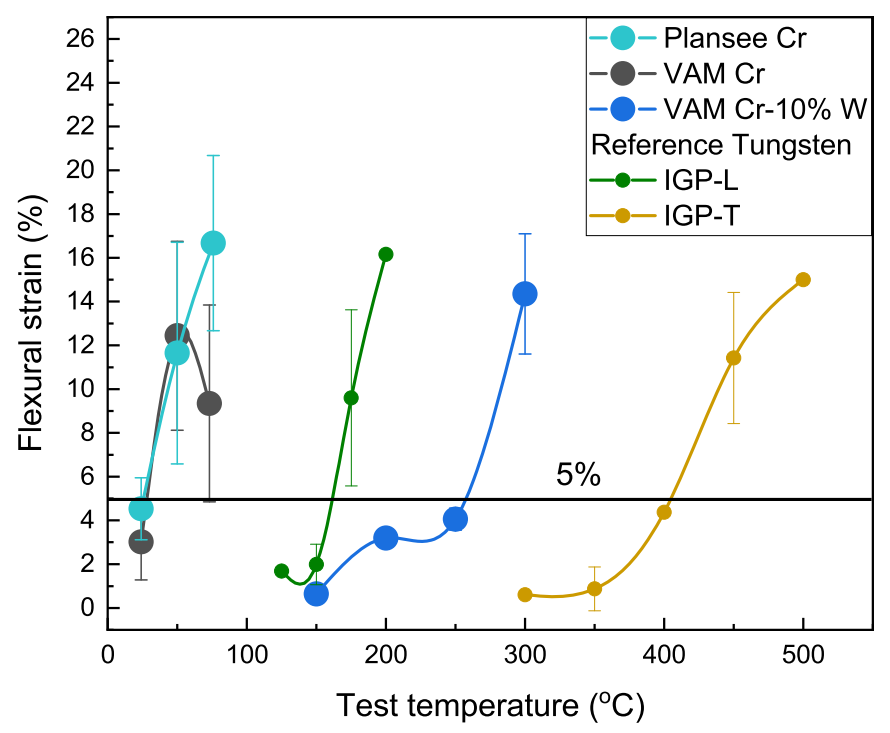

Fig. 4. Dependence of the maximum flexural stain on the test temperature for three $\mathrm{Cr}$ products and pure tungsten (Plansee product is used as reference material in the WPPFC and WP-MAT)

noted trends are valid for both test temperatures.

In addition to the tests performed at elevated temperature, we have applied standard hardness tests using instrumented nanoindentation and Vickers hardness equipment. These types of tests are often used to screen the mechanical properties after irradiation as they are simple/fast and yet allow to link the evolution of the hardness with the change in the flow stress of bulk samples. The hardness deduced from the nanoindentation (using Berkovich indenter) is shown in Fig. 6. When the indentation depth exceeds $\sim 1 \mu \mathrm{m}$, the response of the material is mainly determined by its microstructure (so-called statistically stored dislocations). The standard error on the data shown in Fig. 6 is about 5\% of the absolute value (except low indentation depth, $<200 \mathrm{~nm}$ ), so we do not provide the error bars to avoid obscuring the mean data points. Fig. 6 shows that the saturated hardness (i.e. hardness taken at the depth of $1 \mu \mathrm{m}$ ) of pure $\mathrm{Cr}$ is about 2.85-3 GPa for both VAM and Plansee $\mathrm{Cr}$. The hardness of pure $\mathrm{W}$ is $6.8 \mathrm{GPa}$, which agrees well with the results obtained in earlier studies [33]. The hardness of $\mathrm{Cr}-10 \mathrm{~W}$ is between these two bounds and it yields to $4.05 \mathrm{GPa}$.

In the case of Vickers hardness test, the penetration of the indenter (Vickers pyramid) is much deeper than $1 \mu \mathrm{m}$ achieved in the nanoindentation experiment. The results of the Vickers hardness measurements are presented in Fig. 7 for HV force varied from 0.025 up to $0.2 \mathrm{kgf}$. Different HV force implies different penetration depths of the pyramid (the higher - the deeper, and it reaches $\sim 10 \mu \mathrm{m}$ at $0.2 \mathrm{~kg}$ force in pure $\mathrm{Cr}$ ). Thus, we have screened the response of the material to different values of the HV force to understand whether is there any dependence on the penetration depth. The results show that within the error bars, there is no dependence seen, thus proving the presence of heterogeneous microstructure in all tested materials. Generally speaking of the 

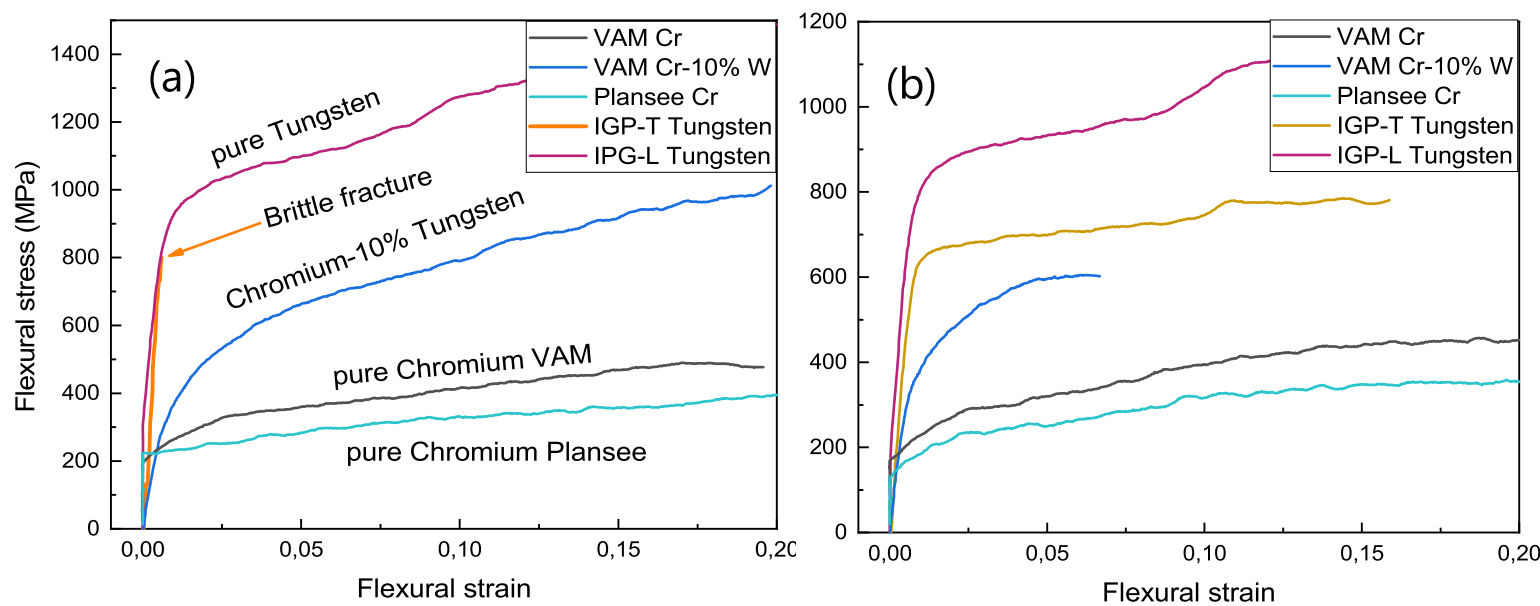

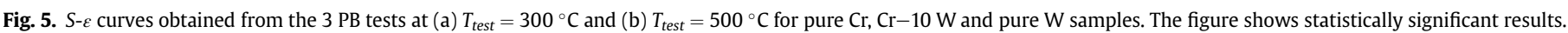
For each test condition, at least three samples were tested.

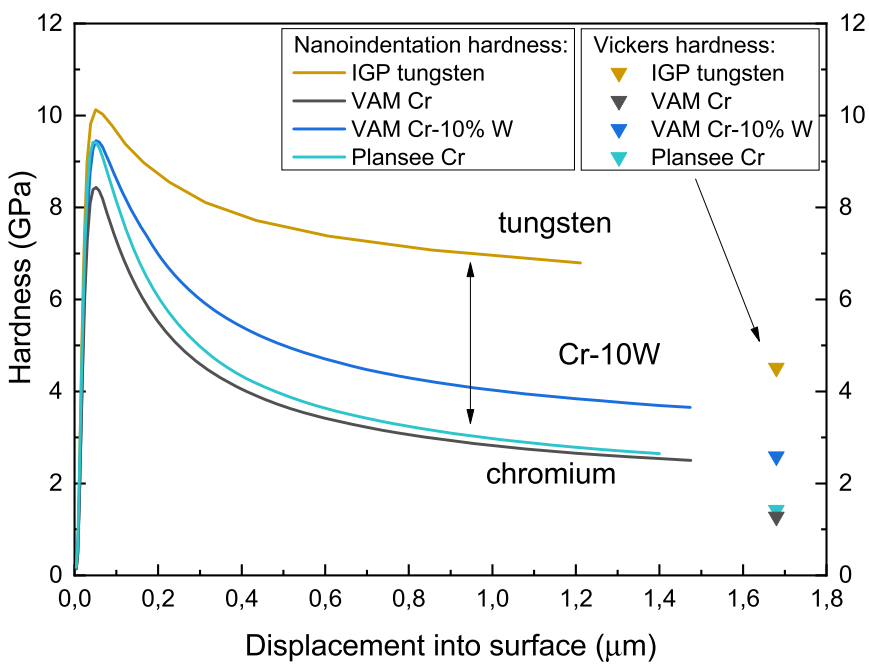

Fig. 6. Hardness versus displacement obtained by nanoindentation. The triangular symbols at $1.7 \mu \mathrm{m}$ (which is just a demonstrative value) show the hardness obtained by Vickers hardness (at HV force $=200 \mathrm{~g}$ ) test after recalculation into units of GPa.

measured hardness values, as in the case of the hardness obtained by the nanoindentation, the highest hardness realizes in $\mathrm{W}$, the lowest one in pure $\mathrm{Cr}$, and the hardness of $\mathrm{Cr}-10 \mathrm{~W}$ product is located in between. Again, we can notice that the hardness measurements for pure tungsten correspond very well to what is published in open literature for the hot rolled pure tungsten [42]. The HV values were recalculated to GPa units and added to Fig. 6 to compare with the nanoindentation measurements. The absolute values of the hardness are lower, as expected since the indented volume is much larger in the Vickers hardness tests, while, the order and relative difference of the hardness values for the tested materials are almost the same as seen in the nanoindentation tests. Hence, we have obtained consistent set of data from HV and nanoindentation tests.

Summarizing the results obtained from the $3 \mathrm{~PB}$, Vickers hardness and nanoindentation measurements we can conclude that (i) both pure $\mathrm{Cr}$ products have similar flow stress, stress-strain response and transition temperature; (ii) alloying of $\mathrm{Cr}$ by $10 \% \mathrm{~W}$ considerably increases the flow stress, which is consistently seen in all performed tests, but also shifts up the transition temperature and limits the bending strain to rupture.

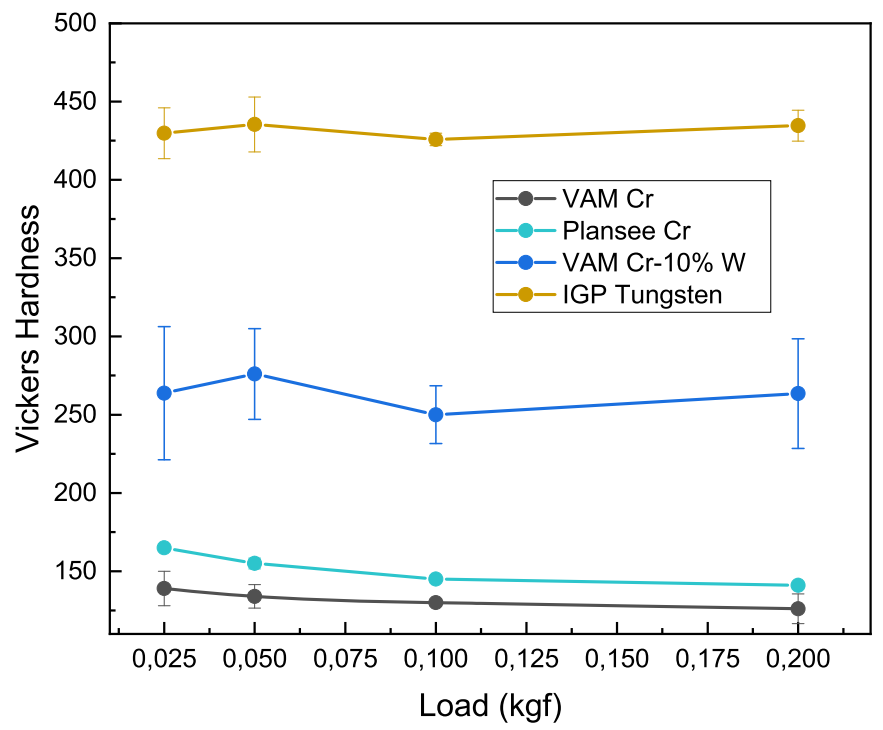

Fig. 7. Vickers hardness obtained for different values of the force applied.

\subsection{Fracture surface}

In this last subsection of Results, we present the analysis of the fracture surface of the $3 \mathrm{~PB}$ samples. A set of SEM images is given in Fig. 8. For each $\mathrm{Cr}$-based material, two images showing the fracture surface below and above the transition temperature are provided. The stress-strain curves for these samples are shown in Fig. 3. Blue arrows show the side at which crack has nucleated and a point to the direction of the crack extension.

The fracture surface of the VAM Cr is shown in Fig. 8 ( $a$ and b). At RT, the fracture surface corresponds to the pure cleavage which extends to about $80 \%$ of the sample cross-section (see, Fig. 8(a)). Above the transition temperature (i.e. at $75{ }^{\circ} \mathrm{C}$, Fig. 8(b)), the crack deflection, cleavage tongs and river patters are clearly seen. The presence of these features indicates the limited tearing resistance as the propagation of a crack involves switching cleavage planes, likely linked to the crack arrest and local plastic deformation. One can also notice the presence of non-negligible macroscopic deformation on the bottom part of the sample (i.e. extension of the sample width).

The fracture surface of the $\mathrm{Cr}-10 \mathrm{~W}$ sample tested at $150{ }^{\circ} \mathrm{C}$ is 


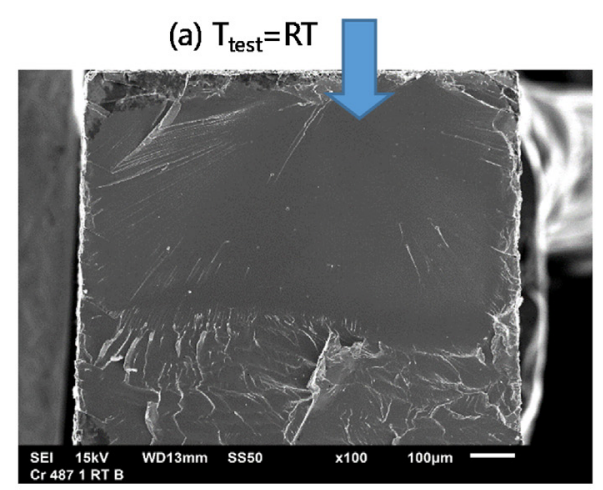

(c) $\mathrm{T}_{\text {test }}=150^{\circ} \mathrm{C}$

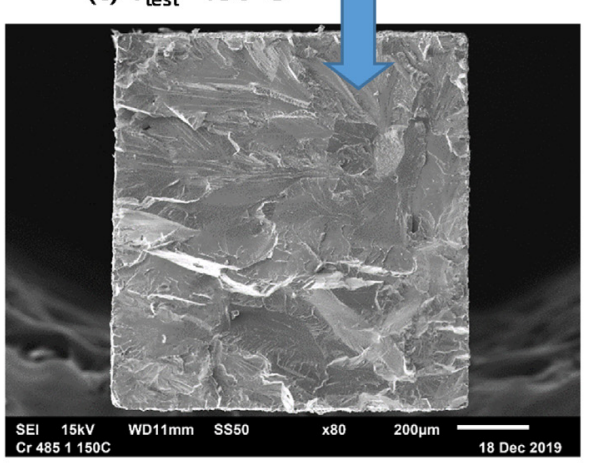

(e) $\mathrm{T}_{\text {test }}=\mathrm{RT}$

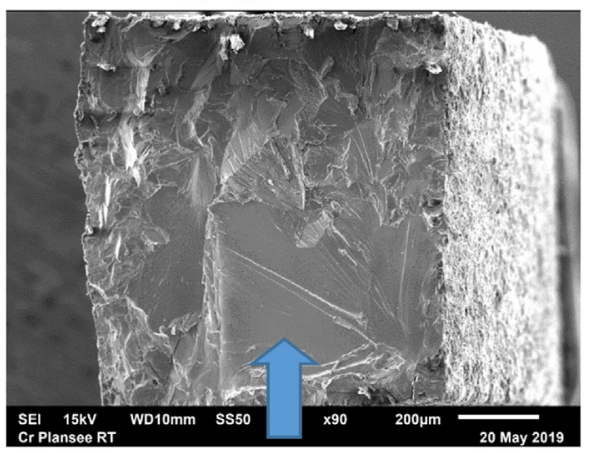

(b) $\mathrm{T}_{\text {test }}=75^{\circ} \mathrm{C}$

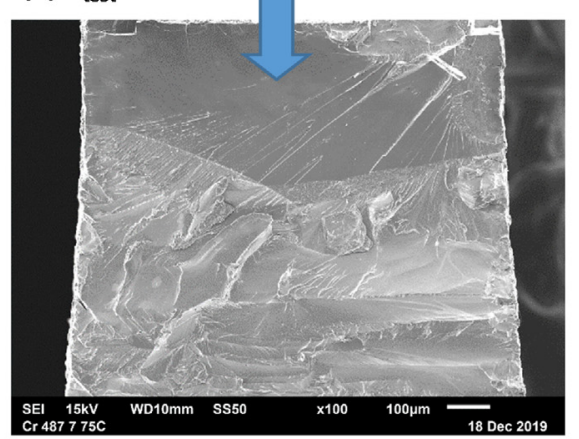

(d) $\mathrm{T}_{\text {test }}=350^{\circ} \mathrm{C}$

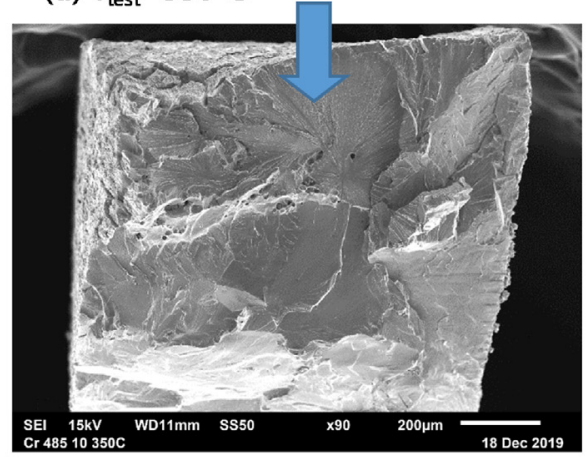

(f) $\mathrm{T}_{\text {test }}=75^{\circ} \mathrm{C}$

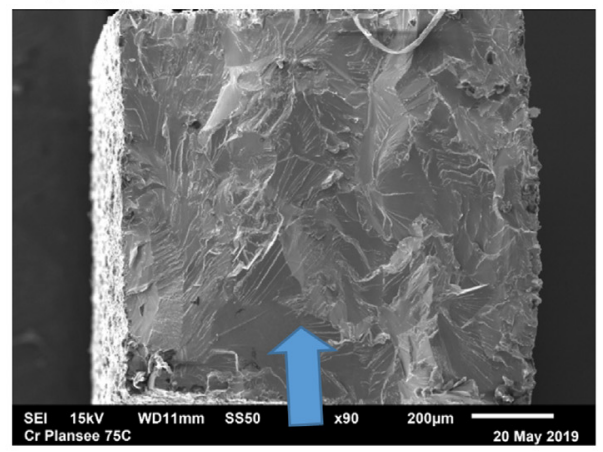

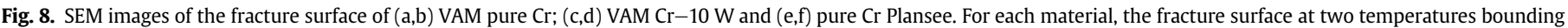

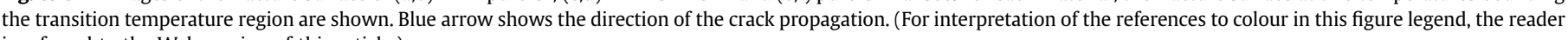
is referred to the Web version of this article.)

shown in Fig. 8(c). The main fracture mode is intergranular fracture, suggesting that the crack propagation and limited plastic deformation is mainly controlled by grain boundaries which apparently suppress the transmission of dislocations. However, at $350{ }^{\circ} \mathrm{C}$ the deflection of the macro-crack path is rather evident, see Fig. 8(d), which reveals the appearance of the plastic deformation causing crack arrest and presence of the tearing resistance before the rupture of the sample takes place. Again, one can notice a considerable macroscopic bending and shear deformation of the sample, confirming the ductile bending deformation observed in the mechanical tests.

The fracture surface of Plansee $\mathrm{Cr}$ is shown in Fig. 8 (e and f). In the brittle temperature range (i.e. RT), a large part of the fracture surface exhibits cleavage pattern. At $75^{\circ} \mathrm{C}$, the fracture surface is of mixed type: trans- and intergranular fracture combination is observed. Multiple river patterns, cleavage steps as well as shear deformation bands on the cleaved surfaces of grains can be observed. As discussed above, the latter features provide an evidence for the crack arrest and deflection, which offers the sample to sustain a certain bending strain well exceeding $5 \%$.

\section{Summary and discussion}

In this contribution we have assessed the potential of vacuum arc melter technology to fabricate chromium and chromiumtungsten alloy for the purpose of structural applications in fusion reactor. Two materials were fabricated as ingots which were then annealed and cut to produce samples for different types of tests. Chemical composition has been investigated by three different methods to ensure that very limited (or ultimately no) oxygen contamination occurred during the fabrication and thermal processing. Mechanical properties were studied by three point bending, Vickers hardness and nanoindentation tests. From the three point bending tests, the transition temperature for ductility was identified using the criterion proposed in Ref. [38], originally developed for tungsten. The scanning electron microscopy was applied to characterize the fracture surface of the materials tested below and above the transition temperature. As a result, the 


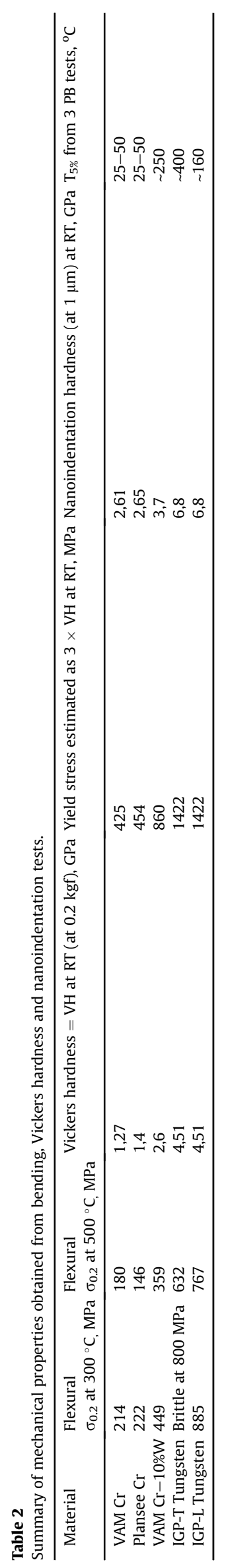

transition temperature for the VAM $\mathrm{Cr}$ was identified in the range $22-50{ }^{\circ} \mathrm{C}$, and for the VAM $\mathrm{Cr}-10 \mathrm{~W}$ to be in the range $250-300{ }^{\circ} \mathrm{C}$.

One of the first studies of the ductile to brittle transition in $\mathrm{Cr}$ were performed by Thornley and Wronski in Ref. [43], who studied polycrystalline $\mathrm{Cr}$ annealed at $1200{ }^{\circ} \mathrm{C}$ for $8 \mathrm{~h}$ by performing tensile tests. The ductility transition temperature is defined as the highest temperature at which $<0.1 \%$ plastic strain was observed and the value found was $\sim 390{ }^{\circ} \mathrm{C}$, which is rather high and apparently it is explained by relatively high oxygen content $(500 \mathrm{ppm})$ in that material. The brittle fracture below $390{ }^{\circ} \mathrm{C}$ was seen as a cleavage (and sometimes grain boundary parting). However, by increasing the test temperature by only $7^{\circ} \mathrm{C}$ shows an entirely different behavior. At $\sim 400{ }^{\circ} \mathrm{C}$, the total elongation reached $25 \%$ and the fracture surface exhibited was a pattern of transgranular and dimple rupture.

Later on, Holzwarth et al. [11] examined the commercially available pure chromium Ducropur (trademark of Metallwerke Plansee AG, Austria, see composition in Table 1). The material was available in a form of plate with a thickness of up to $15 \mathrm{~mm}$, which is comparable to the thickness of the chunks studied here. The grain size of Ducropure was $82 \mu \mathrm{m}$ and no evident texture was reported. The tensile and fracture toughness tests were carried out in air, in the temperature range between room temperature and $1000{ }^{\circ} \mathrm{C}$. Thus, the testing conditions of our study and the one of Holzwarth et al. [11] are nearly equivalent.

Ducropur specimens exhibited significant elongation at fracture and cross section reduction already at test temperatures around $150{ }^{\circ} \mathrm{C}$. However, from the fracture toughness results one would conclude that the DBTT of at least $250{ }^{\circ} \mathrm{C}$, and the fractography revealed the cleavage fracture even at higher temperatures. Variation of the transition temperature from tensile to fracture toughness tests has been discussed by Thornley and Wronski [43] for chromium and tungsten. The brittle failure criterion based on the microscopic plastic deformation was proposed by Bridgman [44] following the tensile testing. Alternatively, according to Orowan [45], the brittle fracture corresponds to the catastrophic crack propagation process, thus the transition temperature is to be derived from fractography analysis and evolution of the fracture toughness (i.e. transition from lower to upper shelf region).

In the present work, the transition temperature to ductile deformation mode is defined on the basis of the microscopic plastic deformation, which is registered as bending of the bar up to a flexural strain exceeding $5 \%$ (referred to as $\mathrm{T}_{5 \%}$ ). The geometry of the used samples does not allow one to define the fracture toughness according to the applicable standards (see e.g. Ref. [36]). However, in our recent study applied for tungsten [31], we have demonstrated that the onset of the ductility of the $3 \mathrm{~PB}$ samples correlates well with the increase of the fracture toughness as well as the change of the fracture surface pattern. Thus, for the purpose of the ductility screening, we consider that the current approach of utilizing $3 \mathrm{~PB}$ tests is sufficient to investigate the impact of the neutron irradiation. Given the small dimension and simple geometry of a specimen, the irradiation in high flux positions with limited volume can be performed for all three types of materials studied here. Investigation of the neutron irradiated materials is our next step. To summarize the properties of the studied materials in non-irradiated condition, we have assembled Table 2 which collects the main information on the mechanical properties obtained by different techniques. All these properties will be re-obtained after the neutron irradiation programme which is currently running.

From Table 2, we can see that at $300{ }^{\circ} \mathrm{C}$ all materials, except tungsten in Transverse orientation, are ductile. However, the 
bending flexural stress at $0.2 \%$ flexural strain (i.e. $\sigma_{0.2}$ ) is 214-222 MPa for pure $\mathrm{Cr}$, while it is nearly four times larger in pure $\mathrm{W}$ (L-orientation has $\sigma_{0.2}-880 \mathrm{GPa}$ ). $\sigma_{0.2}$ of $\mathrm{Cr}-10 \mathrm{~W}$ material is $449 \mathrm{MPa}$, which is in between pure $\mathrm{Cr}$ and pure $\mathrm{W}$. The same trend is observed for the results of the tests done at $500{ }^{\circ} \mathrm{C}$. The increase of the test temperature by $200{ }^{\circ} \mathrm{C}$ leads only to a moderate reduction $(7-15 \%)$ of the $0.2 \%$ flexural strain.

Nanoindentation and Vickers hardness tests performed at room temperature have shown that VAM and pure $\mathrm{Cr}$ exhibit very similar response, as in the case of $3 \mathrm{~PB}$ tests. The $\mathrm{HV}$ (at $0.2 \mathrm{kgf}$ ) of pure $\mathrm{Cr}$ is about a factor of two lower compared to $\mathrm{Cr}-10 \mathrm{~W}$. The hardness of $\mathrm{Cr}-10 \mathrm{~W}$, deduced from both the Vickers hardness and nanoindentation tests, stands in between pure $\mathrm{Cr}$ and pure $\mathrm{W}$.

Finally, the transition temperature for ductility (i.e. $\mathrm{T}_{5 \%}$ ) was identified to be within $25-50{ }^{\circ} \mathrm{C}$ band for both tested pure $\mathrm{Cr}$ grades, $\sim 250{ }^{\circ} \mathrm{C}$ for $\mathrm{Cr}-10 \mathrm{~W}, \sim 160^{\circ} \mathrm{C}$ and $\sim 400^{\circ} \mathrm{C}$ for pure tungsten in longitudinal and transversal orientations, respectively. The uncertainty in the determination of the transition temperature is linked to the selection of a temperature increment in the 3 PB tests. It is interesting to note that despite of the high hardness, $\mathrm{T}_{5 \%}$ of the IGP-L tungsten samples is considerably lower than that of the $\mathrm{Cr}-10 \mathrm{~W}$. This is likely could be attributed to the positive effect of the forging, which ductilizes the material thanks to the introduction of high dislocation density and high volume fraction of low angle grain boundaries. Unfortunately, the forged and hot-rolled materials exhibit rather low temperature threshold for the recovery, since the internal strains assist thermally activated dislocation motion resulting in the reduction of the dislocation density and restructuration of the grain boundaries. In the case of commercially pure tungsten, the threshold temperature is about $1200-1350{ }^{\circ} \mathrm{C}$ (i.e. $T_{m} / 3$, here $T_{m}$ is the melting point), as it was studied in Ref. $[42,46,47]$. In the present case, the studied $\mathrm{Cr}-10 \mathrm{~W}$ was annealed at $2000{ }^{\circ} \mathrm{C}$ (to ensure uniform grain structure and chemical composition) and therefore we do not expect any microstructural changes up to that temperature. Thermal stability and threshold for the recovery of $\mathrm{Cr}$ Plansee plate requires further study.

\section{Conclusions}

On the basis of the obtained results and above discussion, we make the following concluding statements:

(i) As-casted pure $\mathrm{Cr}$ (without any further thermo-mechanical treatment) produced by the VAM technology has shown similar mechanical properties to pure $\mathrm{Cr}$ produced by Plansee, which was fabricated by conventional powder metallurgy by sintering and rolling into a plate of $4 \mathrm{~mm}$. The transition temperature for ductility of both materials is defined to be $25-50{ }^{\circ} \mathrm{C}$.

(ii) As-casted $\mathrm{Cr}-10 \mathrm{~W}$ produced by the VAM has shown much higher strength compared to pure $\mathrm{Cr}$ and capacity for significant work-hardening when tested at elevated temperatures. The transition temperature to ductile deformation mode is around $250^{\circ} \mathrm{C}$. The presence of $\mathrm{W}$ solid solution has a clear impact on the grain size and flow properties of the material. However, in addition to W, EDS examination revealed the presence of Al-rich particles, whose origin is currently unclear (possibly crucible-tungsten interaction). Further investigation is required to clarify the origin of those particles and their impact on the mechanical properties.

(iii) Due to the large grain size of the VAM-produced materials, the transgranular cleavage is often observed near the $\mathrm{T}_{5 \%}$ test temperature. A thermo-mechanical treatment by e.g. cold rolling would result in the increase of the dislocation density and grain refinement, which overall should improve the strength of the materials and reduce the transition temperature simultaneously.

(iv) Currently performed tests have been done to make the first screening of mechanical properties and establish the threshold temperature for ductility on the basis of the microyielding criterion (i.e. to be deduced from tensile or bending tests). The extraction of the fracture toughness according to the ASTM/ISO norms will require further significant efforts (including the fabrication of considerable amount of the material). Prior to proceed, screening bending tests will be applied to the neutron irradiated materials (and compared with Plansee material) using the same methodology as utilized here to characterize the non-irradiated materials.

\section{Declaration of competing interest}

The authors declare that they have no known competing financial interests or personal relationships that could have appeared to influence the work reported in this paper.

\section{CRediT authorship contribution statement}

D. Terentyev: Writing - original draft, Methodology. T. Khvan: Writing - original draft, Methodology. J.-H. You: Conceptualization, Funding acquisition, Writing - review \& editing. N. Van Steenberge: Writing - original draft, Methodology.

\section{Acknowledgements}

The work has been carried out within the framework of the EUROfusion consortium and has received funding from Euratom Research and Training Programme 2019-2020 under grant agreement No. 633053.

\section{References}

[1] W.D. Klopp, Recent developments in chromium and chromium alloys, JMET (J. Med. Eng. Technol.) 21 (1969) 23-32.

[2] W.D. Klopp, Review of chromium, molybdenum, and tungsten alloys, J LessCommon Met 42 (3) (1975) 261-278.

[3] P. Rocco, M. Zucchetti, The impact of low-activation criteria on the development of novel materials for fusion, J. Nucl. Mater. 212 (1994) 649-654.

[4] M. Zucchetti, M. Merola, Low-activation properties of novel Cr-based materials for fusion reactors, J. Nucl. Mater. 233 (1996) 1486-1490.

[5] B. Massalski, Binary Alloy Phase Diagrams, second ed., ASM, Metals Park, OH, 1991, p. 822.

[6] R. Eck, H.P. Martinz, T. Sakaki, M. Kato, Powder metallurgical chromium, Mat Sci Eng a-Struct 120 (1989) 307-312.

[7] H.P. Martinz, R. Eck, J. Eiter, T. Sakaki, M. Kato, Corrosion behavior of powder metallurgically produced chromium, Werkstoffe Korrosion 40 (12) (1989) $715-719$.

[8] reportStandardization of Radioactive Waste Categories, IAEA, Technical Reports Series no. 101 (1970).

[9] E. Gaganidze, H. Schneider, B. Dafferner, J. Aktaa, High-dose neutron irradiation embrittlement of RAFM steels, J. Nucl. Mater. 355 (2006) 83-88.

[10] S.J. Zinkle, J.T. Busby, Structural materials for fission \& fusion energy, Mater. Today 12 (2009).

[11] U. Holzwarth, H. Stamm, Mechanical and thermomechanical properties of commercially pure chromium and chromium alloys, J. Nucl. Mater. 300 (2-3) (2002) 161-177.

[12] W.- Cr, Phase Diagram Bulletin of Alloy Phase Diagrams, vol. 5, 1984, p. 3.

[13] A. Calvo, C. Garcia-Rosales, F. Koch, N. Ordas, I. Iturriza, H. Greuner, G. Pintsuk, C. Sarbu, Manufacturing and testing of self-passivating tungsten alloys of different composition, Nuclear Materials and Energy 9 (2016) 422-429. 
[14] A. Souidi, C. Becquart, C. Domain, D. Terentyev, L. Malerba, A. Calder, D. Bacon, R. stoller, Y. Osetsky, M. Hou, Dependence of radiation damage accumulation in iron on underlying models of displacement cascades and subsequent defect migration, J. Nucl. Mater. 355 (2006) 89-103.

[15] E. Little, D. Stow, Effects of chromium additions on irradiation-induced void swelling in alpha-iron, Metal Science March, 1980, p. 89.

[16] R.L. Klueh, A.T. Nelson, Ferritic/martensitic steels for next-generation reactors, J. Nucl. Mater. 371 (2007) 37-52.

[17] A. Kohyama, A. Hishinuma, D.S. Gelles, R.L. Klueh, W. Dietz, K. Ehrlich, Lowactivation ferritic and martensitic steels for fusion application, J. Nucl. Mater. 233-237 (1996) 138-147.

[18] G. Bonny, D. Terentyev, L. Malerba, Identification and characterization of Crrich precipitates in $\mathrm{FeCr}$ alloys: an atomistic study, Comput. Mater. Sci. 42 (2008) 107-112.

[19] G. Bonny, R.C. Pasianot, E.E. Zhurkin, M. Hou, Determination of the phase diagram from interatomic potentials: the iron-chromium case, Comput. Mater. Sci. 50 (7) (2011) 2216-2220.

[20] G. Bonny, D. Terentyev, L. Malerba, On the $\alpha-\alpha^{\prime}$ miscibility gap of Fe-Cr alloys, Scripta Mater. 59 (2008) 1193-1196.

[21] P. Grobner, The $885^{\circ} \mathrm{F}$ embrittlement of ferritic stainless steels, Metall Trans 4 (1973).

[22] E. Little, void-swelling in irons and ferritic steels I, J. Nucl. Mater. 87 (1979) $11-24$

[23] E.A. Little, R. Bullough, M.H. Wood, ON the swelling resistance OF ferritic steel, Proc. R. Soc. Lond. Ser. A Math. Phys. Eng. Sci. 372 (1751) (1980) 565.

[24] D. Terentyev, L. Malerba, A. Barashev, On the correlation between selfinterstitial cluster diffusivity and irradiation-induced swelling in $\mathrm{Fe}-\mathrm{Cr}$ alloys, Phil. Mag. Lett. 85 (11) (2005) 587-594.

[25] D. Terentyev, M. Klimenkov, L. Malerba, Confinement of motion of interstitia clusters and dislocation loops in BCC Fe-Cr alloys, J. Nucl. Mater. 393 (2009) $30-35$.

[26] D. Gelles, Void swelling in binary Fe-Cr alloys at 200 dpa, J. Nucl. Mater. 225 (1995) 163-174

[27] Y. Konobeev, A. Dvoriashin, S. Porollo, F. Garner, Swelling and microstructure of pure $\mathrm{Fe}$ and $\mathrm{Fe}-\mathrm{Cr}$ alloys after neutron irradiation to $\sim 26 \mathrm{dpa}$ at $400^{\circ} \mathrm{C}$, J. Nucl. Mater. 355 (2006) 124-130.

[28] M. Rieth, D. Armstrong, B. Dafferner, S. Heger, A. Hoffmann, M. Hoffmann, U. Jäntsch, C. Kübel, E. Materna-Morris, J. Reiser, M. Rohde, T. Schrerer, V. Widak, H. Zimmermann, Tungsten as a structural divertor material, Adv. Sci. Technol. 73 (2010) 11-21.

[29] M. Wirtz, J. Linke, T. Loewenhoff, G. Pintsuk, I. Uytdenhouwen, Thermal shock tests to qualify different tungsten grades as plasma facing material, Phys. Scripta T167 (2016), 014015.

[30] C. Yin, D. Terentyev, T. Pardoen, A. Bakaeva, R. Petrov, S. Antusch, M. Rieth, M. Vilemova, J. Matejicek, T. Zhang, Tensile properties of baseline and advanced tungsten grades for fusion applications, Int J Refract Met H 75 (2018) 153-162.
[31] C. Yin, D. Terentyev, T. Pardoen, R. Petrov, Z.F. Tong, Ductile to brittle transition in ITER specification tungsten assessed by combined fracture toughness and bending tests analysis, Mat Sci Eng a-Struct 750 (2019) 20-30.

[32] W. Oliver, G. Pharr, J. Mater. Res. 19 (2004) 3-20.

[33] D. Terentyev, A. Bakaeva, T. Pardoen, A. Favache, E.E. Zhurkin, Surface hardening induced by high flux plasma in tungsten revealed by nano-indentation, J. Nucl. Mater. 476 (2016) 1-4.

[34] L. Tanure, A. Bakaeva, L. Lapeire, D. Terentyev, M. Vilemova, J. Matejicek, K. Verbeken, Nano-hardness, EBSD analysis and mechanical behavior of ultrafine grain tungsten for fusion applications as plasma facing material, Surf. Coating. Technol. 355 (2018) 252-258.

[35] D. Terentyev, L. Tanure, A. Bakaeva, A. Dubinko, V. Nikolic, J. Riesch, K. Verbeken, S. Lebediev, E.E. Zhurkin, Micromechanical and microstructural properties of tungsten fibers in the as-produced and annealed state: assessment of the potassium doping effect, Int J Refract Met H 81 (2019) 253-271.

[36] ASTM, E, in: 399 -12, Standard Test Method for Linear-Elastic Plane Strain Fracture Toughness KIC of Metallic Materials, ASTM international, 2012. E 399-12.

[37] ASTM, E290 -14, Standard Test Methods for Bend Testing of Material for Ductility, E2vols. 90 -14, ASTM international, 2014.

[38] D.H. Lassila, F. Magness, D. Freeman, Ductile-Brittle Transition Temperature Testing of Tungsten Using the Three-Point Bend Test, Report Lawrence Livermore National Laboratory UCRL-ID-108258 (1991).

[39] Z.M. Xie, R. Liu, S. Miao, X.D. Yang, T. Zhang, X.P. Wang, Q.F. Fang, C.S. Liu, G.N. Luo, Y.Y. Lian, X. Liu, Extraordinary high ductility/strength of the interface designed bulk W-ZrC alloy plate at relatively low temperature, Sci Rep-Uk 5 (2015).

[40] V. Krsjak, S.H. Wei, S. Antusch, Y. Dai, Mechanical properties of tungsten in the transition temperature range, J. Nucl. Mater. 450 (1-3) (2014) 81-87.

[41] J. Reiser, S. Wurster, J. Hoffmann, S. Bonk, C. Bonnekoh, D. Kiener, R. Pippan, A. Hoffmann, M. Rieth, Ductilisation of tungsten (W) through cold-rolling: Rcurve behaviour, Int J Refract Met H 58 (2016) 22-33.

[42] M. Yu, K. Wang, X. Zan, W. Pantleon, L.M. Luo, X.Y. Zhu, Y.C. Wu, Hardness loss and microstructure evolution of 90\% hot-rolled pure tungsten at 1200-1350 degrees C, Fusion Eng. Des. 125 (2017) 531-536.

[43] J.C. Thornley, A.S. Wronski, The failure of po/crystalline chromium between 657 and 706 K. Met. Sci. J. 6 (1972) 1217-1221.

[44] P.W. Bridgman, J. Appl. Phys. 18 (1947) 246.

[45] E. Orowan, Rep. Prog. Phys. 12 (1948) 185.

[46] A. Alfonso, D.J. Jensen, G.N. Luo, W. Pantleon, Recrystallization kinetics of warm-rolled tungsten in the temperature range 1150-1350 degrees C, J. Nucl. Mater. 455 (1-3) (2014) 591-594.

[47] P. Zhao, J. Riesch, T. Hoschen, J. Almanstotter, M. Balden, J.W. Coenen, R. Himml, W. Pantleon, U, von Toussaint, R. Neu, Microstructure, mechanical behaviour and fracture of pure tungsten wire after different heat treatments, Int J Refract Met H 68 (2017) 29-40. 